\section{Replacement of percutaneous endoscopic gastrostomy: pierce to replace}

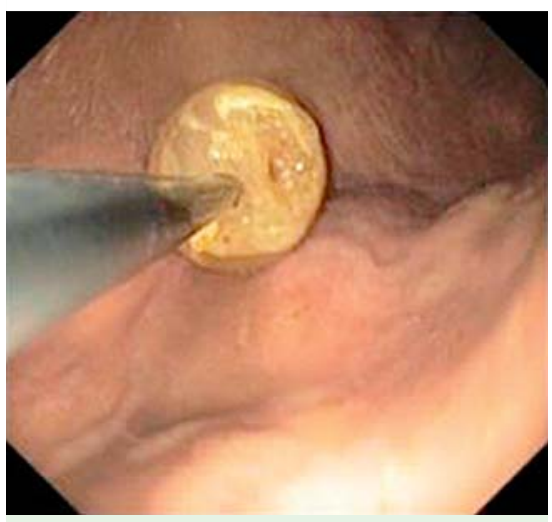

Fig. 1 Balloon puncture of the percutaneous endoscopic gastrostomy (PEG) retention device following failure to aspirate the saline during PEG replacement.

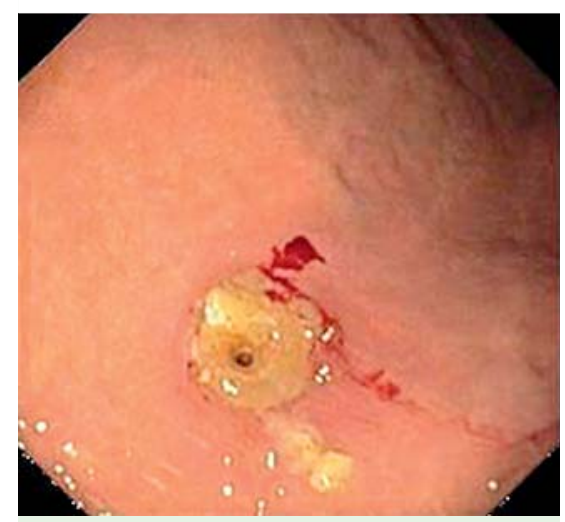

Fig. 2 The balloon was punctured during upper endoscopy, with only minor trauma to the mucosa.

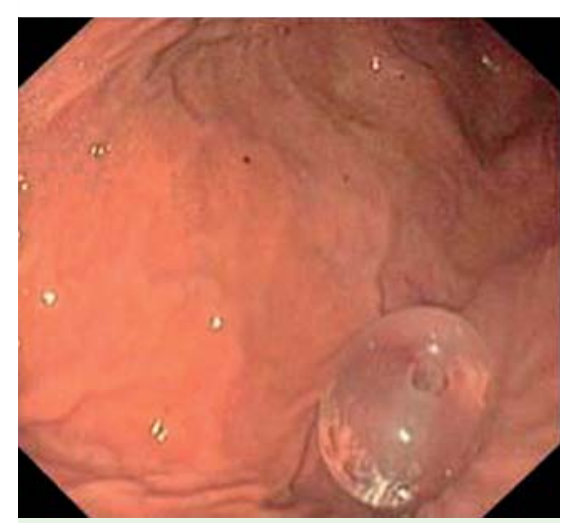

Fig. 3 A new balloon in place following percutaneous endoscopic gastrostomy replacement.
A 69-year-old man underwent placement of a conventional percutaneous endoscopic gastrostomy (PEG) device in 2011 for dysphagia due to neurological impairment. The device was replaced 2 years later with one that had a balloon filled with saline solution as its internal retention mechanism. In January 2014, another balloon PEG replacement was scheduled. However, it was not possible to aspirate the saline solution and remove the internal bolster through the gastrostomy tract. Due to the risk of buried bumper syndrome, it was decided to perform an upper endoscopy to locate the filled balloon and puncture it with an injector needle inserted through the endoscope. With this technique, the PEG device was removed without complications, such as bleeding or laceration of the stoma. This was the second case of this peculiar complication to occur within a year; on both occasions, the case was managed in the same way.

None of the available literature on complications related to the management of PEG devices describes the complete obstruction of the filling channel of the balloon. In the present case, balloon emptying was achieved by inserting an injector needle through the endoscope and puncturing the balloon, allowing the solution to drain away. This safe and quick technique - pierce to replace - has not been reported previously.

Endoscopy_UCTN_Code_CPL_1AH_2AI

Competing interests: None

\section{Amadeu C. R. Nunes, Armando Peixoto,} Guilherme Macedo

Gastroenterology Department, Centro Hospitalar de São João, Porto, Portugal

Bibliography

Dol http://dx.doi.org/

10.1055/s-0034-1377371

Endoscopy 2014; 46: E382

(c) Georg Thieme Verlag KG

Stuttgart · New York

ISSN 0013-726X

Corresponding author

Amadeu C. R. Nunes, MD

Gastroenterology Department

Centro Hospitalar de São João

Porto 4200-319

Portugal

Fax: +351-225-025766

ascrnunes@gmail.com 